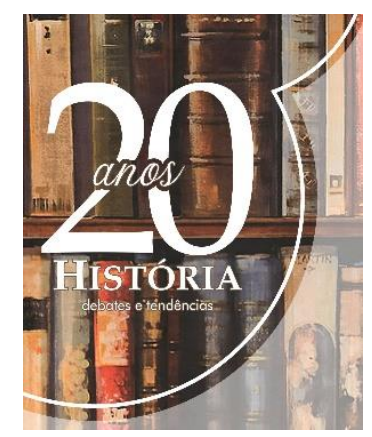

\title{
María en altares de Oshun: pedidos y ex-votos en contextos de hibridación cultural (Zárate y Campana)
}

\author{
Maria nos altares de Oshun: pedidos e ex-votos em contextos de \\ hibridação cultural (Zárate e Campana)
}

\section{Mary in Oshun altars: religious orders and ex-votos in contexts of cultural hybridization (Zárate and Campana).}

Patricia A. Fogelman ${ }^{\mathbf{i}}$

\begin{abstract}
Resumen: Analizaré los altares dedicados a Oshun, orishá del Batuque, en Zárate y Campana (Provincia de Buenos Aires, Argentina), enfocando sobre aquellos que incluyen representaciones de la Virgen María. El culto mariano tiende a expandirse en América Latina a través de numerosas vías. Es llamativa la presencia de sus imágenes mezcladas o reapropiadas por la religiosidad de matriz africana provenientes del Brasil. Porosidad en creencias y prácticas, presencia de desplazamientos e hibridaciones entre las ofrendas en los altares serán investigadas en su doble perfil: de fuentes visuales pasibles de indagación histórica (atendiendo a las funciones de la imagen) y en lo que hace a su calidad de exvotos de reconocimiento por gracias hipotéticamente recibidas. Espero contribuir al área de los estudios culturales de la religión contemporánea desde un enfoque histórico sobre el Batuque en relación con la dinámica del culto mariano. Las imágenes (fotografías de altares) serán las principales fuentes.
\end{abstract}

Palabras clave: Historia de la religión. Oshun. Virgen María.

Resumo: São analisados os altares dedicados a Oxum, Orishá do Batuque, Zárate e Campana (Província de Buenos Aires, Argentina), focando aqueles que incluem representações da Virgem Maria. O culto mariano tende a expandir-se na América Latina de várias formas. É impressionante a presença de suas imagens misturadas ou reapropriadas pela religiosidade da matriz africana do Brasil. Porosidade nas crenças e práticas, e a presença de deslocamentos e hibridizações entre as ofertas nos altares serão pesquisadas no seu duplo perfim de fontes visuais passíveis de investigação histórica (dependendo das capacidades da imagem) e que faz a sua qualidade de ex-votos, de reconhecimento por graças hipoteticamente recebidas. Se deseja contribuir para a área de estudos culturais da religião contemporânea a partir de um foco histórico no Batuque em relação à dinâmica do culto mariano. As imagens (fotografias dos altares) serão as principais fontes.

Palavras-chave: História da religião. Oshun. Virgem Maria.

\footnotetext{
Abstract: We will analyze the altars dedicated to Oshun, orishá del Batuque, in Zárate and Campana (Province of Buenos Aires, Argentina), focusing on those that include representations of the Virgin Mary. The Marian cult tends to expand in Latin America through numerous ways. It is striking the presence of their images mixed or reappropriated
} 
by the religiosity of African origin stemming from Brazil. We will investigate how beliefs and practices can affect each other, as well as the presence of displacements and hybridizations between the offerings in the altars from two different aspects: the visual sources that are amenable to historical inquiry (taking into account the functions of the image) and in respect to their quality as votive offerings of recognition for the hypothetically received graces. We hope to contribute to the area of cultural studies of contemporary religion from a historical perspective of the Batuque in relation to the dynamics of the Marian cult. The images (photographs of altars) will be our main research sources.

Keywords: History of religion. Oshun. Virgin Mary.

\section{Introducción}

Quienes estudiamos la religión sabemos se ella se expresa en términos muchas veces ambiguos en las fronteras de las prácticas devocionales. Las religiones tienden a establecer continuidades, rituales, normatividades, circulación de creencias y de prácticas, tanto como innovaciones y desplazamientos entre distintas matrices. Los cultos de origen africano en Brasil son escenario de numerosas hibridaciones desde sus inicios hasta la actualidad. La historiografía brasileña da cuenta desde hace décadas de esa riqueza y de ese movimiento.

En Argentina, el culto a los orishás es mucho más reciente y ha sido abordado en primer lugar, por sociólogos y antropólogos (por ejemplo: FORNI, 1986, 4-24; FRIGERIO 1993; FRIGERIO y CAROZZI, 1994, 7-16; CAROZZI y CERIANI CERNADAS, 2007, 20-41; MARTÍN, 2007, 61-86; CERIANI CERNADAS, 2008; AMEIGEIRAS, 2008).

Los historiadores hemos comenzado a aproximarnos a estas modulaciones de las creencias y las prácticas religiosas con posterioridad a nuestros colegas (TOURIS, 2010, 123-146; FOGELMAN, 2010. 9-18 y 2015, 07-23), y mucho más recientemente aún a enfocarnos sobre la historicidad del fenómeno de matriz africana. También en la Argentina el culto a los orishás presenta las complejidades de un contacto fuerte con la matriz cristiana (católica, en general) que, como un sustrato importante, lo precede y se mezcla por contacto en las prácticas concretas. Este espacio del ritual y la construcción de la creencia en particular lo consideraremos como un contexto de hibridación de matrices religiosas aludiendo a la idea de la hibridez de las culturas en el traspaso de la tradición hacia la modernidad (GARCÍA CANCLINI, 1989).

En este artículo analizaremos especialmente los altares dedicados a Oshun, orishá del Batuque, donde aparecen representaciones de la Virgen María. ${ }^{\text {ii }}$ Como sabemos, el culto mariano es muy pregnante y tiende a expandirse en América Latina a través de numerosas vías. Es llamativa la presencia de sus imágenes mezcladas o reapropiadas por 
la religiosidad de matriz africana que nos llega desde el Brasil. Porosidad en creencias y prácticas, presencia de desplazamiento e hibridaciones entre las ofrendas en los altares serán investigadas en su doble perfil: de fuentes visuales pasibles de indagación histórica (atendiendo a las funciones de la imagen) y en lo que hace a su calidad de exvotos de reconocimiento por gracias hipotéticamente recibidas. Entre los cientos de orishás existentes en África Oshun ha sido uno de los pocos que han sido trasladados con gran facilidad a las nuevas formas de adoración y fusión cultural americanas. Puede encontrarse el culto a Oshun en rituales de Candomble, Santería cubana, Tradicionalismo o Ifá y, como analizaremos, en rituales de Batuque. Además es posible identificarla como una figura relevante en el culto Umbanda, surgido en Brasil en 1908.

El espacio elegido son diferentes templos de Batuque radicados en las ciudades de Zárate y Campana, Provincia de Buenos Aires.

Esperamos contribuir al área de los estudios culturales de la religión contemporánea desde un enfoque histórico que de cuentas del arribo del Batuque a la región, sus principales características y la conformación de un conjunto de rituales donde el catolicismo en su rama mariana es reapropiado en una forma dinámica y creativa.

Nos centraremos en las prácticas de los actores religiosos que son especialmente los Pai o Mae de Santo, practicantes del batuque que responden principalmente a la veneración del orishá Oshun por encima de otros Orisas. En este sentido, otra noción fundamental como instrumento de análisis es la idea de representación que deriva de los aportes de Louis Marin a través de Roger Chartier (CHARTIER, 1996, 73-99).

Las imágenes, especialmente las fotografías de los altares, son las principales fuentes para este ejercicio. Y dentro de ellas, enfocaremos especialmente a las imágenes de la Virgen María en relación con la figura femenina de Oshun para pensar los motivos de ese cruce y las características de estos desplazamientos en el contexto del ritual actual en parte de la zona norte de la provincia de Buenos Aires.

\section{La llegada del batuque a norte de la Provincia de Buenos Aires. El espacio de la devoción}

Los cultos afroamericanos en la Argentina se han desarrollado desde 1970 en una sociedad que poco conoce este fenómeno.

La consolidación de vínculos internacionales, las nuevas formas de comunicación 
y el avance de la globalización han contribuido a la instalación de instituciones religiosas batuqueras, umbandistas y de línea cruzada (Quimbanda) provenientes de Brasil, así como sus variantes uruguayas y otras líneas de culto vinculadas a la tradición Yoruba africana.

Estos cultos, independientemente de la variante analizada se centran en la adoración de un Dios supremo denominado Olodumare considerado el creador. Esta adoración cuenta con la mediación de los Orisas, representaciones humanizadas de diferentes aspectos de la naturaleza (Yemanja es dueña de los mares; Osanyin es dueño de las hierbas; Bará representa el movimiento y dinamismo del universo, etc.).

Existen pocas investigaciones en esta área temática para la Argentina y entre ellas se destaca notablemente el aporte de Alejandro Frigerio quien, desde la Antropología, ha abierto un camino que los historiadores aún no hemos recorrido, y esta ponencia espera contribuir en ese sentido.

Hemos elegido abordar el estudio de los desplazamientos entre el catolicismo y el batuque a través de las imágenes marianas en los altares de Oshun en Zárate y Campana (Prov. De Buenos Aires) debido a la desinformación general que existe alrededor de ese procesolocal, y también porque consideramos interesante el cruce entre el catolicismo (en particular, las devociones marianas) y el sustrato del batuque en el contexto de prácticas mezcladas de la religiosidad.

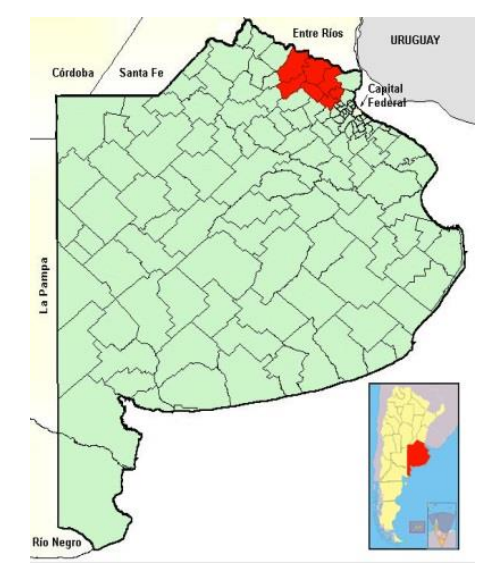

Fig. 1. La llegada del batuque a norte de la Provincia de Buenos Aires.

El espacio de la devoción

En cuanto a la región que nos compete, debemos señalar que está conformada por dos núcleos urbanos de mediana densidad poblacional, asentada en un espacio que alguna vez fue agrícola y que actualmente cuenta con la presencia de empresas multinacionales que se ubicaron en la zona por el Puente Complejo Zárate-Brazo Largo, que vincula el 
litoral argentino con el Mercosur. Allí, las principales empresas son Toyota, Honda, Techint, Terminal Zárate (portuaria), entre otras. El río Paraná atraviesa la región separando Zárate de Campana. El mismo facilita un flujo de mercancías e influencias culturales que han permitido el arribo del batuque a esta región del norte de la Provincia de Buenos Aires. En este caso, la tradición religiosa local es mayoritariamente católica y, dentro de ella, el culto a la Virgen del Carmen viene gozando de gran popularidad. Por otro lado, desde Zárate sale anualmente una rama importante de fieles que converge con la mayor peregrinación de la Argentina, que va hacia la Basílica Nacional de Luján. Como se puede observar, el culto mariano es preponderante y es la base donde consideramos se asienta la incorporación del batuque que ha llegado del Brasil desde hace algunas décadas.

\section{Los altares de Oshun. Agradecimientos y mezclas}

Por razones de espacio, en este trabajo sólo nos referiremos a tres altares de Oshun porque son los que contienen imágenes de la Virgen María entre las ofrendas realizadas, dos de ellos en Zárate y uno en Campana.

El primer caso, corresponde a un altar en la ciudad de Zárate y remite a una mesa de agradecimiento a Oshun realizada el día 8 de diciembre, lo cual hace coincidir la celebración con la fiesta de la Inmaculada Concepción. En este altar observamos la presencia una imagen mariana que se corresponde con una estatuilla de la Inmaculada Concepción ataviada y adornada con elementos propios del batuque: un manto amarillo y una guirnalda dorada a modo de collar, que son del color de los clásicos atributos de Oshun. Además, en el altar, observamos un perfumero, campanillas (sinetas utilizadas para invocar en los diferentes cantos o rezas), caramelos, flores y un velón amarillos. La Virgen Inmaculada, vestida de amarillo, ocupa un lugar central en el altar "bendiciendo" la mesa, lo cual significa que recibió las ofrendas que se le dieron en días anteriores durante los rituales de faena y a su vez, ella ofrece el alimento para todo el "pueblo" (entendemos el pueblo como feligresía y amigos que acompañan). Es interesante pensar las posiciones relativas en el escenario del ritual, donde la Virgen Inmaculada (reiteramos, ataviada como Oshun) se destaca en medio de un desplazamiento de sentido religioso mientras que al fondo, observamos la presencia de otro Orishá femenino: nos referimos a Yemanjá, quien también suele ser reconocida sincréticamente con otra advocación mariana, en este caso, Stela Maris del Mar. Se trata de una imagen de tamaño menor que la primera, y en una posición secundaria en esta festividad y, por lo tanto, en 

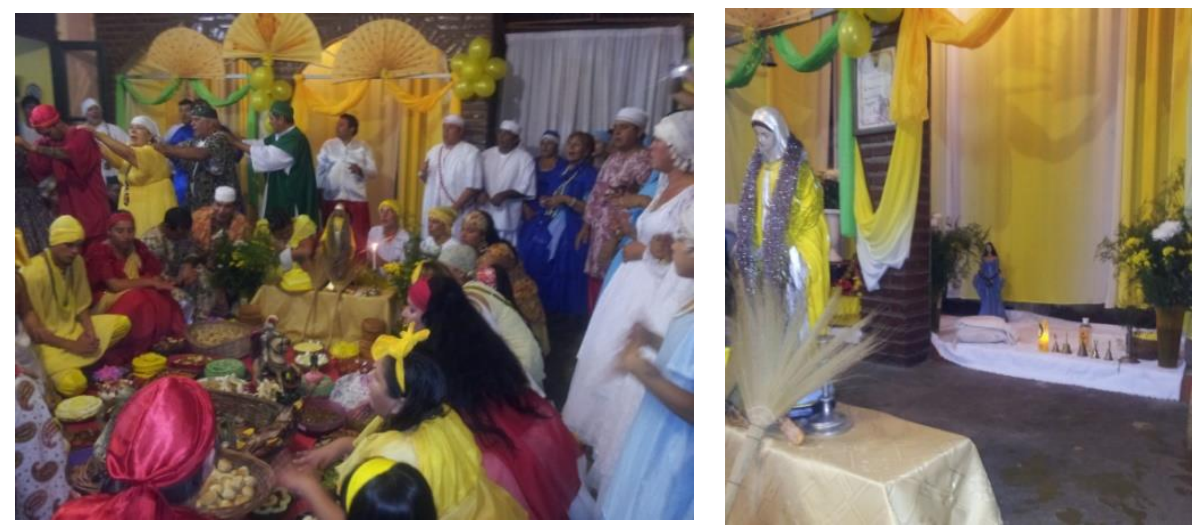

Figs. 2 y 3. Los altares de Oshun. Agradecimientos y mezclas. Zárate, 8/12/15.

Fotografías: Lucía German

Además, en el frente (lo que podría suponer otro tipo de jerarquía)encontramos la figura de São Jorge de Capadocia, comúnmente identificado con el orishá masculino Ogún, guardando una línea recta que conduce a la principal imagen que es la de María / Oshun. En parte, la explicación de esta particular configuración de escena se corresponde probablemente con el hecho de que el nombre completo del Pai Miguel es "de Oshún Epanda"; es decir, que su santo de cabeza es el orishá Oshun. Por otro lado, la figura de Stela Maris (que no es central) tiene presencia porque en los templos de Batuque se busca representar a todos los orishás mediante diferentes elementos como estatuillas, herramientas de trabajo características del orishá o "guías de colores" (collares que indican jerarquías). Sabemos que los hijos de cada orishá se visten con los colores correspondientes pero nos interesa señalar el juego, las líneas cruzadas, de identificación entre las imágenes y los fieles. En el sentido de la apropiación de un conjunto de caracteres que demarca la pertenencia a una familia, a un linaje, en este caso, no circunscripto a un templo (familia/templo) sino a la ascendencia de un orishá sobre un conjunto de individuos. Pai y Mãe explicitan esa relación filial pero también una jerarquía particular que se trasunta también en el uso del espacio y la disposición de las imágenes que se interrelacionan. El espacio ritualizado es una construcción con forma de constelaciones de imágenes cambiantes según las celebraciones y donde la gente también toma posiciones y destaques. Son dos ruedas concéntricas formadas por iniciados y subrayamos que en la más cercana a la mesa giran los devotos de Oshun (con prioridad) e hijos de otros orishás que han realizado ofrendas rituales. 


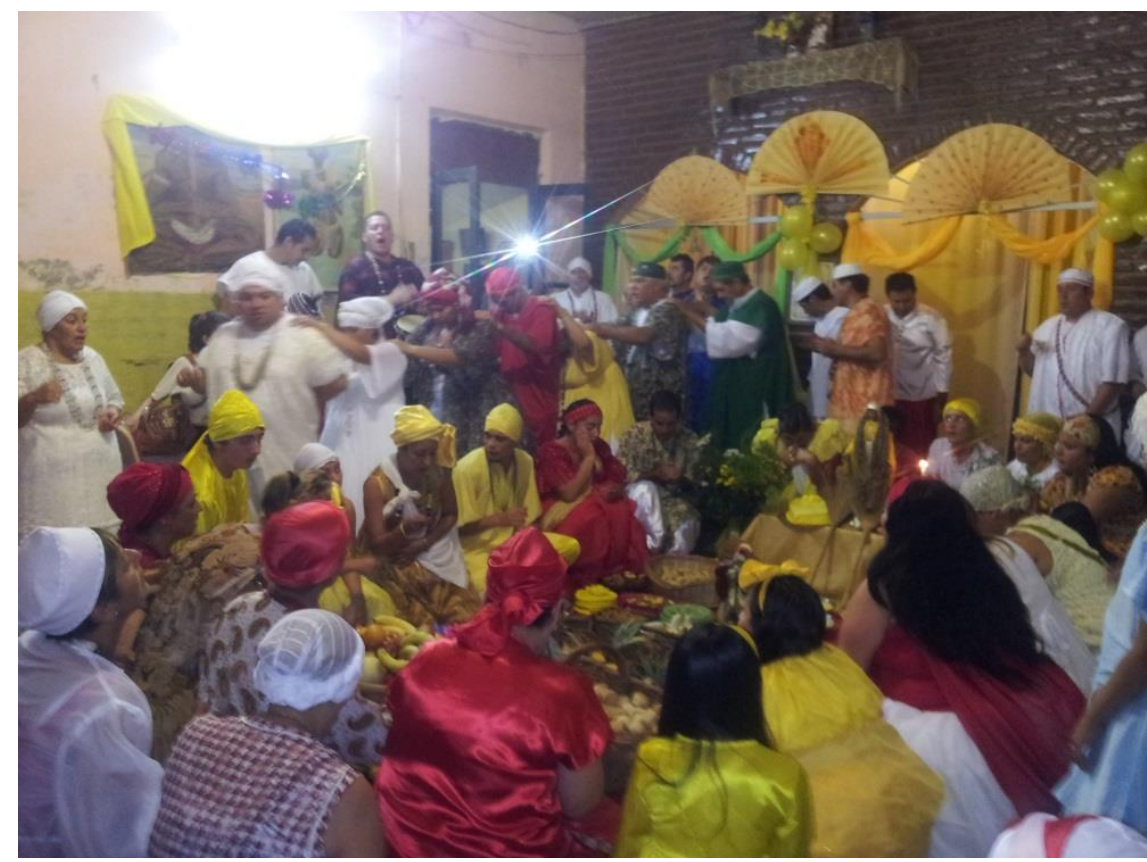

Fig. 4. Los altares de Oshun. Agradecimientos y mezclas. Zárate, 8/12/15. Fotografía: Lucía German

La peculiar presencia de la mezcla del amarillo y el rojo entre los feligreses expresa visualmente el vínculo privilegiado entre Oshun y Bará y la trasposición de ese lazo entre las personas. Para llegar a la riqueza que ofrece Oshun es conveniente seguir los caminos abiertos por Bará. Entre los fieles, esta "asociación” se refleja en el escenario del ritual tal como lo vemos en la foto.

Entre los atributos de Oshun se destacan los abanicos, el espejo, el peine y las joyas de latón o de cobre. En esta tradición cultural (tanto como en la de Occidente), los "afeites y bisutería" se asignan a los roles de género femenino (esto, en la particular configuración histórica sobre los sexos a partir de una mirada binaria de ellos). Sin discutir ese hecho y aceptándolo como tal, vemos que Oshun porta un espejo tal como la Virgen María en su advocación Inmaculada se destaca en la iconografía por el uso del mismo elemento (entre muchos otros). Es más, en esta tradición mariana, ella es espejo de Justicia, vidrio pulido sin defecto que refleja la santidad o los estados de perfección. El espejo, entonces, puede ser tenido en cuenta como un elemento común que intersecciona ambas tradiciones culturales favoreciendo el desplazamiento entre una y otra en la práctica. Colores, joyas, perfumes son apelaciones concretas a los sentidos que envuelven las ceremonias.

En el conjunto de fotografías tomadas durante la celebración de Oshun encontramos la presencia de una barca amarilla que representa una ofrenda que debe ser llevada al río, que es su morada. En ese sentido, la ofrenda es un agradecimiento anual. Reflexionando sobre la naturaleza de estas ofrendas dudamos si clasificarla o no como exvotos, pues se trata de un agradecimiento calendárico que no ata a los fieles mediante 
el lazo de una rogativa particular y una gracia concedida "ad hoc". Sin embargo, en este caso esta ofrenda es colectiva y da cuenta de la unidad de intereses de varios miembros en su confección. Es, además, una ofrenda propiciatoria: combina el pedido con el agradecimiento en el mismo objeto y la misma acción. En esta barca vemos el predominio de los colores amarillo y dorado, característicos de Oshun (aluden a la riqueza, al oro especialmente), pero también hay monedas, joyas (sobre todo, collares), alimentos dulces $^{\mathrm{iii}}$ (de color amarillo o anaranjando), abanicos, flores, peine, espejos y -muy llamativamente- una imagen de la Virgen María en su advocación de la Inmaculada Concepción.

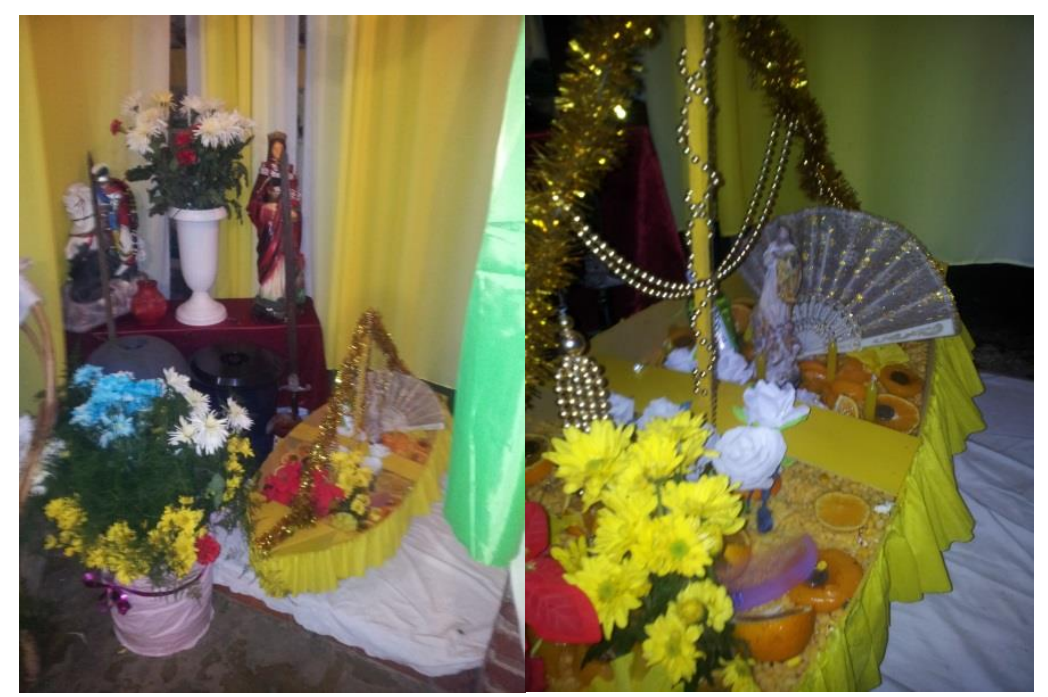

Figs. 5 y 6. Los altares de Oshun. Agradecimientos y mezclas. Zárate, 8/12/15.

Fotografías: Lucía German

Entre las semejanzas de una matriz religiosa y otra (nos referimos al catolicismo y al batuque) encontramos que la figura de la barca es también, para la construcción dogmática marianista, un elemento discursivo central por lo menos desde la intervención de Duns Scoto en su Defensa de la Inmaculada Concepción de la Virgen María dictada en la Universidad de la Sorbonna en el siglo XIV. En esa apología, Scoto afirmaba citando a San Hipólito, mártir- que Jesús:

era un arca de maderas incorruptibles (...). Y por esta arca, exenta de podredumbre y corrupción, se significa su tabernáculo, que no engendró corrupción de pecado. Pues el Señor estaba exento de pecado y estaba, en cuanto hombre, revestido de maderas incorruptibles, es decir, de la Virgen y del Espíritu Santo, por dentro y por fuera, como de oro purísimo del Verbo de Dios. (SCOTO, S. XVI) ${ }^{\mathrm{iv}}$

Es decir, en la lógica argumentativa que mencionamos, Cristo exime del pecado original a su Madre, y ésta lo trae en su vientre -también como una barca- de manera 
excepcionalmente inmaculada.

La barca, en este caso, es también una metáfora de María portando al Cristo en la tradición marianista. Y ese elemento es fácilmente asimilable al que percibimos en la ofrenda periódica para Oshun. En ese sentido, la fecha celebratoria del día 8 de diciembre, coincide significativamente entre una y otra religión propiciando intersecciones de sentido que generan prácticas concretas de desplazamiento pero de matrices semejantes.

En segundo lugar observaremos un altar casero (perteneciente a una familia), donde se ve la conjunción de elementos marianistas y africanos, también en la ciudad de Zárate.

Se trata de un espacio de oración individual en el cual se evidencian diversos objetos personales de veneración, entre los que preponderan aquellos vinculados a Oshun, pero sin dejar de lado otras tradiciones reflejadas en las estampas que se encuentran en el marco superior derecho de la fotografía, aunque las mismas no se visualizan correctamente.

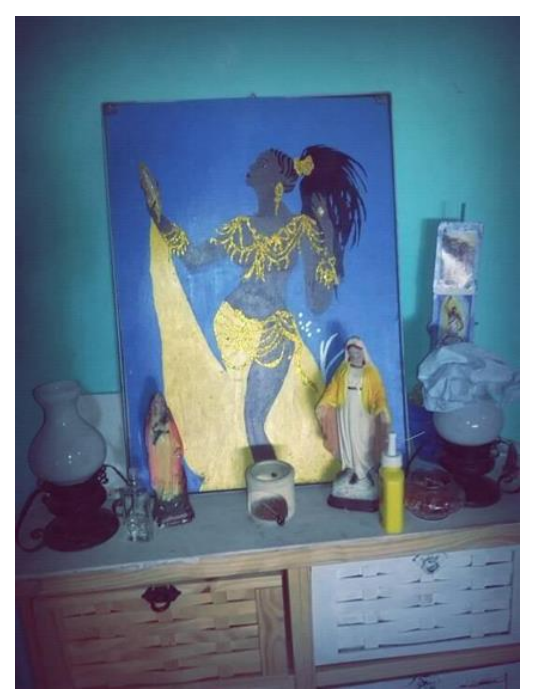

Fig. 7. Altar de Oshun. Zárate, 8/12/15. Fotografía: Lucía German

En este espacio la representación africanista del orishá Oshun se impone centralmente en un cuadro pintado a mano que la muestra con sus ropajes característicos en tonos amarillo y dorado: en su mano derecha sostiene un espejo, mientras que la izquierda se ve adornada con un anillo, además porta aros, joyas colgantes en el área del pecho y un moño en el cabello del mismo color. La imagen exalta notablemente las formas femeninas del cuerpo aunque cubre tenuemente el área de los pechos.

La figura de yeso de mayor tamaño es una representación mariana de la Inmaculada, cubierta por un manto amarillo que probablemente se trate de un "retoque" sobre un manto blanco o celeste. Su ubicación, enmarcada dentro de los límites del cuadro, parece reforzar este paralelismo en el cual dos elementos diferentes representan un mismo concepto: la figura femenina que enlaza a María con Oshun. 
Este altar es un oratorio particular asentado sobre un mueble común (una cajonera), iluminado con dos "veladores" (luces clásicas de dos mesas de noche) que rodean el cuadro central, en el medio hay un hornillo sin porta-esencia que funge de luminaria, acompañado por un perfume y un frasco amarillo que no sabemos qué contiene (probablemente miel) y un recipiente de cristal conteniendo flores.

A la izquierda hay otra estatua más pequeña de una santa cuya denominación no advertimos, pero sí vemos que porta la palma del martirio.

En el centro, como hemos dicho, se destaca la enorme presencia de Oshun pero es evidente el juego de relaciones entre las tres partes femeninas del oratorio. La sensualidad de la representación del orishá contrasta con el clásico recato de las vestimentas marianas, como si la idea de santidad no revistiera los mismos atributos. El dorado, la riqueza, se desplaza del marco del batuque hacia la imagen mariana, vistiéndola de amarillo, resignificando también esa iconografía. Los desplazamientos no son sólo en un sentido, como podemos apreciar sino que la iconografía popular contemporánea del catolicismo recibe transferencias sobre el soporte concreto de la representación.

Es posible que el fondo azul del cuadro sea resultado de una elección arbitraria de quien lo pintó. No hay modo de saberlo. Pero ciertamente ese efecto visual nos lleva a asociarlo con un fondo celestial (más apropiado para pensar la figura de María en la iconografía cristiana) o un fondo de agua, lo que podría asimilarse a la morada de Oshun en el río. La simetría se rompe con la irrupción de las dos estampas (santinhos) cuyos personajes no llegamos a identificar. Suponemos, no obstante, que se trata de dos figuras masculinas.

El tercer caso que analizaremos remite a una celebración de "despacho", es decir, de entrega de barcas con ofrendas para Oshun realizada también el día 8 de diciembre en la ciudad de Campana. Las fuentes utilizadas no son sólo fotografías publicadas en el portal de noticias "Campana online" bajo el nombre "[misterios] El africanismo festejó el día de la Nuestra Señora de la Concepción en la Costanera con giros y ofrendas al río"v, sino que recurriremos además el texto elaborado por los cronistas que cubrieron el evento. 

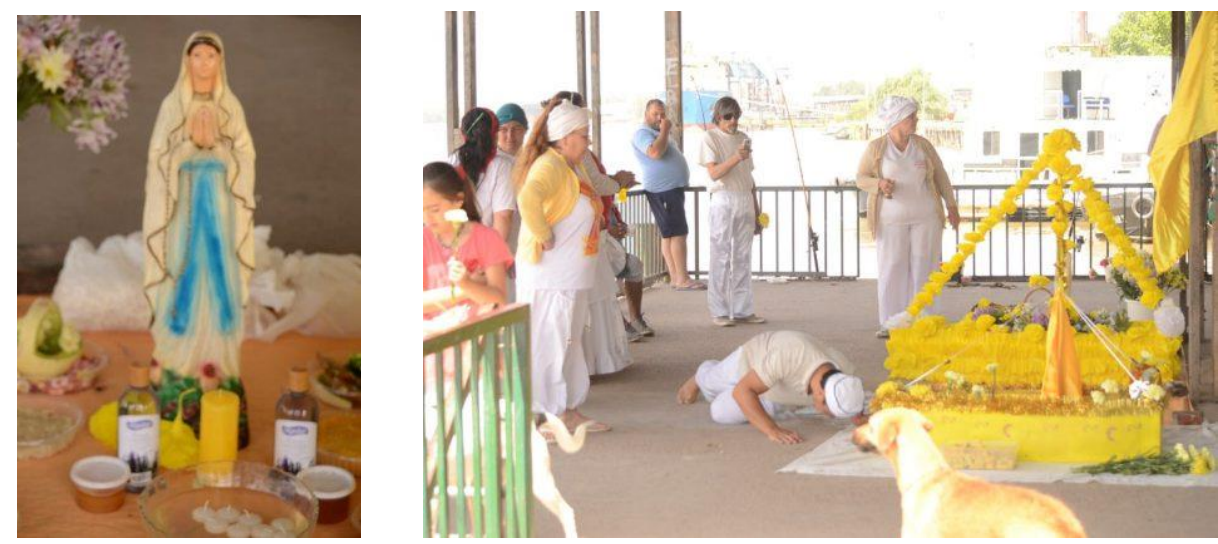

Figs. 8 y 9. Altar y entrega de barca. Campana8/12/16 vi

En estas imágenes observamos en primera instancia el pequeño altar, espacio armado sobre un mantel, que expone elementos típicos e icónicos vinculados a Oshun:

Una imagen mariana correspondiente a la Inmaculada Concepción de María como eje central del conjunto, velas blancas y velones amarillos, frascos de perfume, pétalos de flores y recipientes conteniendo miel. Es destacable además la presencia de ofrendas compuestas por alimentos como un melón ahuecado y relleno con miel y flores blancas, mazamorras blancas y amarillas y pese a no verse con claridad hallamos otro tipo de comidas en el margen superior derecho.

En la segunda fotografía observamos, al igual que en otra festividad analizada el día 8 de diciembre, dos barcas confeccionadas para Oshun ante las cuales uno de los fieles realiza un saludo de "batido de cabeza vii" debido a que esta ofrenda representa desde el inicio de la festividad un objeto sagrado que actúa como comunicador entre los fieles y el orishá. Es necesario destacar que pese a que algunos practicantes portan ropas de tonalidades amarillas, es el color blanco el que prepondera, las personas por lo tanto no visten sus trajes rituales de Batuque, lo que nos permite concluir que se trata de un ritual de hibridación entre los cultos de Umbanda y Batuque. En este sentido el cronista explica: "En la primera parte del ritual africanista, llaman a espíritus a través de bailes mientras todos se encuentran vestidos con atuendos blancos. (...)En Campana todos los 8 de diciembre, festejan el día con rituales y ofrecimientos al río". viii

La figura de Oshún es de suma importancia en ambos cultos, ya que mientras que en Batuque como orishá se le efectúan pedidos por la protección de niños, negocios y para obtención de riquezas, en el culto de Umbanda su carácter de orishá fue apropiado de manera diferente convirtiéndose Oshun en quien dirige de uno de los pueblos de espíritus moradores de los ríos (caboclos), que llegan a los terreiros de Umbanda para purificar a los congregados mediante el poder sanador de las aguas.

Debido a que este trabajo se centra en las relaciones existentes entre Oshun como 
orishá batuquero y sus conexiones con la figura de la Virgen María consideramos que explayarnos aquí exigiría una investigación diferente en muchos aspectos, sin embargo es prudente reconocer estas conexiones dentro del universo de la conformación de los cultos afro.

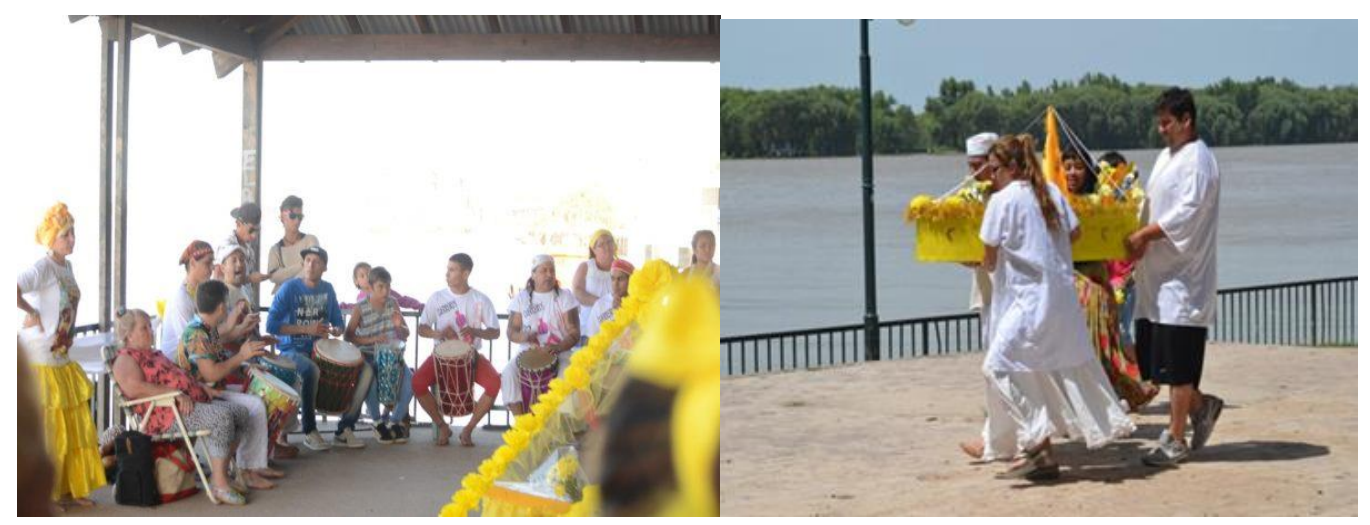

Figs. 10 y 11. Altar y entrega de barcas. Campana, 8/12/16 ${ }^{\text {ix }}$

Luego de la ceremonia de Umbanda este conjunto de fieles procedió a llevar las barcas hacia el río para ser entregadas, como explicamos anteriormente, en calidad de agradecimiento o pedido.
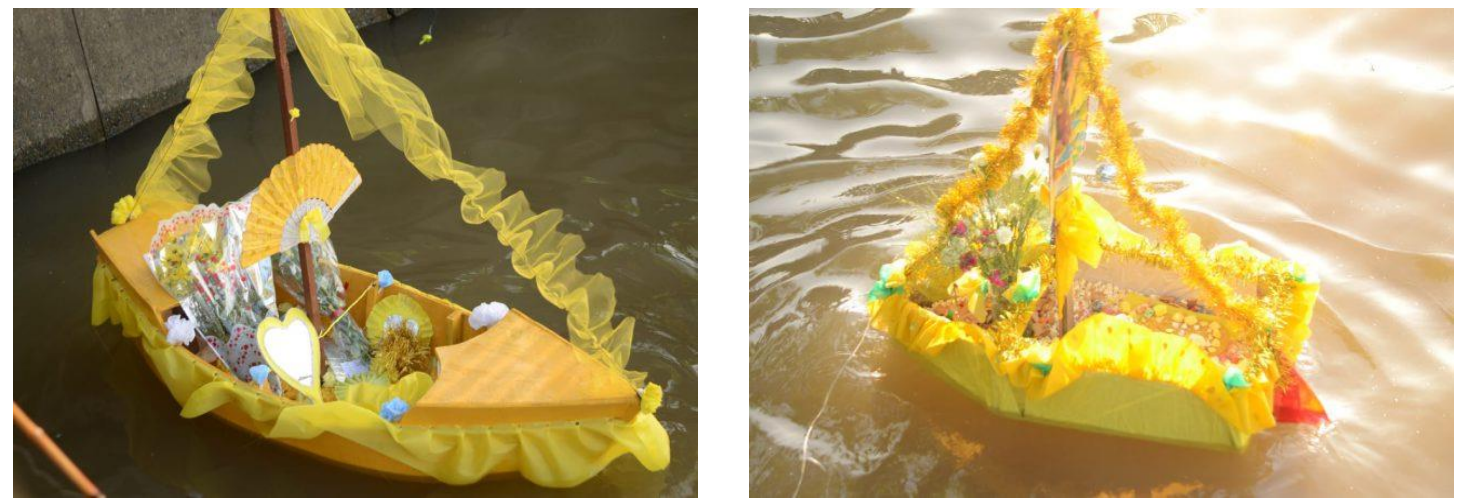

Figs. 12 y 13. Altar y entrega de barcas. Campana, 8/12/16

Las barcas, de características similares a las analizadas en el primer caso, presentan elementos en común 'como por ejemplo el maíz de mazamorra amarillo que se ubica en el piso de ambas, flores, adornos en amarillo y dorado. Además las típicas herramientas de Oshun como abanicos, espejo en forma de corazón e incluso en la segunda imagen se observa de costado una característica estampa de Oshun que es posible adquirir en santerías. Presentamos aquí una representación parecida del mismo personaje. 


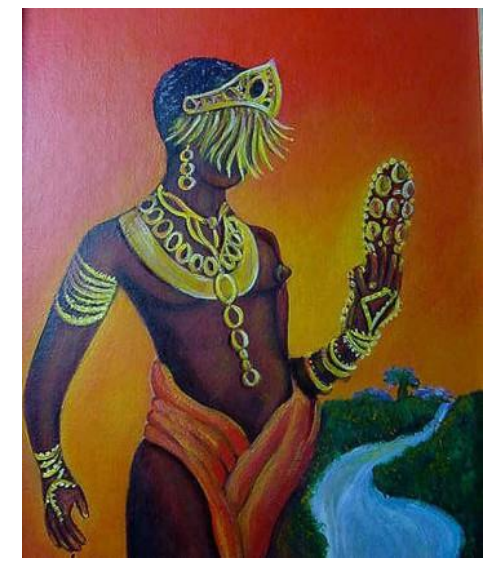

Figs. 14. Imagen de Oshun

En este conjunto de fotografías que conforman tanto el ritual como el altar podemos ver la preponderancia de elementos de los cultos Batuque y Umbanda.

El escenario que rodea el altar es diverso ya que puede observarse un grupo de tambores, devotos que participan de la ceremonia y personas que acompañan sin vestimentas rituales. Las ofrendas rodean el altar central en donde se encuentra la imagen de la Virgen Inmaculada tal y como lo hemos descrito.

Al desarrollar este trabajo surgieron varias preguntas en cuanto a la naturaleza de las ofrendas hechas a Oshun. Así, entendimos que las ofrendas o ebós son actos espirituales privados, que se desarrollan en un espacio colectivo. Por su condición de acto individual, cada persona puede dar a su ofrenda la condición de propiciatoria (haciendo pedidos), o de exvoto de agradecimiento por un favor o gracia recibidos. El Pai Miguel de Oxum Epanda, sacerdote de Oshun dijo que “(...) las ofrendas son mediaciones, son puentes de oración entre el mundo material con lo espiritual.”

Es cierto pueden advertirse otras mediaciones: por ejemplo, la de Bará quien se supone recibe la ofrenda y se la entrega a Oshun. Vemos algunas similitudes entre las representaciones y acompañamientos observadas con anterioridad en el plano coreográfico y simbólico del ritual de batuque Gegé Nagó. Tanto en el ritual de danza para los Orixás, como en las ofrendas a ellos, se pueden establecer lazos de afinidad para el éxito ritualístico. La Mae Gloria de Oxum, practicante de la línea de Oió en la ciudad de Campana, expresó en este sentido algunas ideas similares, aunque más rigurosas: en línea de Oio (las ofrendas) son básicas y generalmente se agrada con ebó una vez que el pedido está resuelto y a la vez se le da a Oxalá Babá porque todo es ancestral y se trabaja con cada dinjinas (nombres) de Oshun Docó. Cada pasaje de Oshun tendrá diferentes dinjinas dependiendo del orixá adjunto y a diferencia de Oshun Adocó, Oshun Epanda y Oshun Epandá Ibeiji tienen como adjuntos a Bará Agelú y Xangó Adganjú. Según los rituales practicados en Oió, se agradece con ebó luego de haber resuelto un problema o 
recibido un pedido. Se va ofrendar a Oshun y al orixá adjunto del religioso que realizó el ritual.

Es posible apuntar que pese a pertenecer a líneas de culto diferentes el rasgo cooperativo y la conjunción energética es similar en ambos templos. Se observa una sutil diferencia en la línea de Oió al poder calificarla, según la entrevistada, como una línea de culto de ofrendas de tipo exvoto.

\section{Conclusiones: Apropiaciones marianas, pregnancia de la figura de la Madre}

En este análisis preliminar en el que abordamos los exvotos y los altares de Oshun en Zárate y Campana pudimos corroborar los desplazamientos de las representaciones marianas hacia la esfera del batuque principalmente y, luego, algunas pequeñas modificaciones en la imagen mariana al calor de las prácticas de origen afrobrasileño. Probablemente, esta afirmación no sea novedosa en el cuadro de las prácticas batuqueras brasileñas pero en la Argentina (y particularmente en la provincia de Buenos Aires) se trata de un desplazamiento novedoso. Consideramos que estas fusiones en torno a la imagen de Oshun y María son propiciadas por un sustrato simbólico común, el de la figura femenina, particularmente, asimilada a la figura materna en ambos lados del binomio. La idea de "una madre" es fuertemente pregnante: todos queremos -o anhelamos tener- una madre, en todas las culturas. Y esta es la clave del éxito que el culto mariano en muchos países iberoamericanos. En la región de Zárate-Campana, el culto a la Virgen del Carmen tiene una larga tradición y es hegemónico entre las representaciones marianas de la religiosidad popular católica. El río Paraná de Las Palmas articula el espacio y se presta también para ser símbolo de la representación de Oshun. Mujer, madre, espejo, río, barca, exvotos/ofrendas son piezas fundamentales en una construcción de sentido que va del sustrato católico existente a la reconfiguración de las creencias y prácticas del nuevo Batuque local que se expresa consistentemente en la apropiación del día de la Inmaculada Concepción para la celebración de Oshun. No podemos dejar pasar que la devoción inmaculista (que enfatiza la excepcionalidad de María exenta del Pecado Original) es la más importante y expandida no en la región, sino en el orbe católico. Ese éxito proviene, como hemos demostrado en otros trabajos, de las campañas en su defensa promovidas desde el siglo XVII en adelante y reconocida como dogma de fe recién a mitad del siglo XIX. Más allá de la coexistencia entre diferentes advocaciones marianas (y aunque incrustaciones locales hayan dado relevancia a otras figuras) la Inmaculada alcanza una pregnancia mayor en la religiosidad de los fieles incluso, aunque ellos no comprendan 
del todo bien su significado. La eximición del pecado original en María suele ser confundida popularmente con su virginidad, dando (a contrapelo de sus implicancias teológicas) una empatía entre los fieles que la sienten como purísima. Así, los creyentes y la devoción popular asimilan temas y advocaciones diferenciadas en una única representación que confunde el sentido dogmático mariológico. Al mismo tiempo, su carácter virginal convierte a María en un difícil modelo a seguir pero fuertemente atractivo y potente.

Los desplazamientos, comunes entre advocaciones marianas diferentes dentro del catolicismo, se complejizan y enriquecen al expandirse por contacto con las figuras femeninas provenientes de la tradición afrobrasileña, mezclando a Oshun y María en formas nuevas que se expanden incluso, más allá de las fronteras nacionales arribando a la Provincia de Buenos Aires y, muy probablemente (hay que continuar la investigación) hacia el interior de la Argentina demostrando la vitalidad y la hibridez de las formas de la creencia en la actualidad.

\section{Referências}

AMEIGEIRAS, Aldo Rubén. Religiosidad popular. Creencias religiosas populares en la sociedad Argentina. Buenos Aires, UNGS. 2008.

CAROZZI, Maria Julia y CERIANI CERNADAS, César (coords.). Ciencias Sociales y Religión en América Latina. Perspectivas en Debate. Buenos Aires, Biblos, 20-41. 2007.

CERIANI CERNADAS, César. "La religión en la encrucijada de los usos y sentidos", en: IX Congreso Argentino de Antropología Social. Posadas, Universidad Nacional de Misiones. Edición electrónica: http://caas.org.ar/images/excursiones/mesa10religion/ponencia\%20ceriani.pdf. 2008.

CHARTIER, Roger. "Poderes y límites de la representación. Marin, el discurso y la imagen”, Escribir las prácticas. Foucault, de Certeau, Marin. Buenos Aires: Manantial. 7399. 1996.

FOGELMAN, Patricia. 2010. "Prólogo: La religiosidad y el poder desde la perspectiva de los estudios culturales", en: Fogelman, Patricia (Comp.). Religiosidad, Cultura y Poder. Temas y problemas de la historiografía reciente. Buenos Aires, Ediciones Lumiere / GERE / COLMICH. 9-18.

FOGELMAN, Patricia Alejandra. "La religión como objeto de análisis: sobre el concepto y tres vías de abordaje histórico". In: Revista Brasileira de História das Religiões. ANPUH, Ano VII, n. 21, 07-23. (Jan/Abr de 2015).

FORNI, Floreal. "Reflexión sociológica sobre el tema de la religiosidad popular", en Sociedad y Religión, N³, Buenos Aires, CEIL-PIETTE, 4-24. 1986. 
FRIGERIO, Alejandro (Comp.). Nuevos Movimientos religiosos y ciencias sociales (I). Buenos Aires, CEAL. 1993.

FRIGERIO, Alejandro y Carozzi, María Julia. “¿El regreso de la religión?: Su estudio a fines del siglo XX", en: Frigerio, Alejandro y Carozzi, María Julia (comps.). El Estudio Científico de la Religión a fines del Siglo XX. Buenos Aires, CEAL, 7-16. 1994.

GARCÍA CANCLINI, Néstor. Culturas híbridas: Estrategias para entrar y salir de la modernidad. México: Grijalbo. (1989).

MARTÍN, Eloísa. “Aportes al concepto de "religiosidad popular”: Una revisión de la bibliografía argentina”, en: Carozzi, María Julia y Ceriani Cernadas, César (Coords.). Ciencias Sociales y Religión en América Latina: Perspectivas en debate. Buenos Aires, Biblos. 61-86. 2007.

TOURIS, Claudia. "La Historiografía de la religión sobre Argentina contemporánea. Núcleos consolidados, aportes recientes y debates en curso", en: Patricia Fogelman (Comp.). Religiosidad, Cultura y Poder. Temas y problemas de la historiografía reciente. Buenos Aires, Ediciones Lumiere / GERE / COLMICH. 123-146. 2010.

Submetido: $14 / 09 / 2019$

Aprovado : 20/11/2019

Publicado: 23/12/2019

\section{Notas}

\footnotetext{
' Patricia Fogelman es doctora en Historia por la École des Hautes Études en Sciences Sociales de París (EHESS) y por la Universidad de Buenos Aires (UBA). Realizó cuatro estancias post-doctorales (tres en Brasil: UFES, UNISINOS, UNIVERSO, y una en la EHESS de París). Es investigadora Independiente en el CONICET. Dicta Historia de Brasil en la UBA. Coordina dos grupos de investigación: GERE (Grupo de Estudios sobre Religiosidad y Evangelización) y GEHBP (Grupo de Estudios de Historia de Brasil y Portugal). E-mail: pafogelman@yahoo.com.ar

ii Este trabajo se desarrolla en el marco de un Proyecto Plurianual de CONICET bajo mi dirección "Devoción mariana en perspectiva comparada: Imágenes, exvotos y relación con lo sagrado en el imaginario católico de Argentina y Brasil" y ha contado con el invalorable aporte de Lucía Rosa Germán (UNLu), quien participó del relevamiento documental, en el trabajo de campo y colaboró en la versión preliminar de este texto.

iiiEn este caso, observamos la presencia de alimentos dulces lo que evidencia la falta de faena de animal para esta parte del ritual. En el caso de Zárate encontramos mazamorra de maíz amarillo con miel, duraznos en mitades, trozos de naranja, etc. 3234

iv https://mercaba.org/TEOLOGIA/OTT/309-338_tratado_de_la_madre_del_redentor.htm

v Artículo completo disponible en la web: Campana online, "[misterios] El africanismo festejó el día de la Nuestra Señora de la Concepción en la Costanera con giros y ofrendas al río". 9 de diciembre 2016. http://campanaonline.com/misterios-el-africanismo-festejo-el-dia-de-la-nuestra-senora-de-la-concepcion-enla-costanera-con-giros-y-ofrendas-al-rio/

vi Campana online, “[misterios] El africanismo festejó el día de la Nuestra Señora de la Concepción...”.

vii El "Batido de cabeza" es un ritual utilizado en los cultos de Batuque y Umbanda en señal de respeto por los espacios sagrados o los miembros religiosos de mayor jerarquía.

viii Campana online, "[misterios] El africanismo festejó el día de la Nuestra Señora de la Concepción..."

ix Campana online, “[misterios] El africanismo festejó el día de la Nuestra Señora de la Concepción...”.

x Campana online, “[misterios] El africanismo festejó el día de la Nuestra Señora de la Concepción...”.
} 